\title{
Surface Antigens of Gonococci: Correlation with Virulence and Serum Resistance
}

\author{
By RAQUEL DEMARCO DE HORMAECHE, ${ }^{*}$ MARGARET J. THORNLEY \\ AND ALISON HOLMES \\ Department of Pathology, University of Cambridge, Tennis Court Road, \\ Cambridge CB2 $1 Q W, U . K$.
}

(Received 26 April 1982; revised 26 October 1982)

\begin{abstract}
Encapsulated and non-encapsulated variants of one strain of gonococcus were compared for their capacity to produce infection in chambers implanted subcutaneously in mice, for their reactions with specific antibody and for their precipitation with wheat germ agglutinin. Only the encapsulated variant could infect implanted chambers. Specific rabbit antiserum raised against the non-encapsulated variant killed only that variant, whereas antibody raised against the encapsulated variant killed both variants.

Saline extracts and lipopolysaccharide preparations of the encapsulated variant differed from those of the non-encapsulated one in their reactions with wheat germ agglutinin and antibody in diffusion and electrophoresis tests. Preparations from infective encapsulated gonococci reacted with wheat germ agglutinin while those from the non-encapsulated variant did not. Immunodiffusion tests showed that lipopolysaccharides from both variants share a common antigenic determinant, but saline extracts and lipopolysaccharides from encapsulated gonococci possess an additional determinant. The significance of these findings is discussed.
\end{abstract}

\section{INTRODUCTION}

Gonococci in urethral pus are more infective than those subcultured in vitro. The inoculation of human urethral exudates containing gonococci into the urethra of human volunteers (Mahoney et al., 1946) or chimpanzees (Lucas et al., 1971) results in an infection which closely resembles gonorrhoea. Cultured gonococci often fail to produce symptoms of urethritis (Mahoney et al., 1946; Brown et al., 1972), suggesting that gonococci in urethral pus have some characteristics which are different from those of cultured organisms. Animal-adapted gonococci are also more infective in subcutaneous chambers than those grown in vitro and this is unrelated to the presence of pili on their surface (Arko et al., 1976; Penn et al., 1976).

Gonococci recently isolated from patients (Ward et al., 1970) or guinea-pig chambers (Penn et al., 1976) are more resistant to serum killing than those subcultured in the laboratory and it seems possible that gonococci in vivo may possess a virulence factor which renders the bacteria less sensitive to the bactericidal or opsonic action of serum.

Both gonococcal LPS and, to a lesser extent, outer membrane proteins have been shown to be the target for bactericidal antibodies (Ward et al., 1978). Lambden et al. (1979) recently reported changes in surface proteins which may be of importance in serum resistance and Guymon et al. (1978) suggested that resistance might be determined by alteration of the LPS structure. Although such variations in LPS could explain differences in virulence and serum resistance they have not been previously demonstrated since the four colony types of gonococci possess an apparently identical 'rough' type LPS (Perry et al., 1978). It is also possible that encapsulation might determine serum resistance as capsules would block the reaction between bactericidal

Abbreviations: KDO, 2-keto-3-deoxyoctulosonic acid; WgA, wheat germ agglutinin. 
antibodies and outer membrane antigens. Capsules could also increase gonococcal virulence by interference with opsonization and phagocytosis and free capsular material or slime might neutralize antibody at a distance from the gonococcal cells. That encapsulation might be involved in resistance to serum killing and phagocytosis has already been suggested (Ward et al., 1978; Richardson \& Sadoff, 1977), but the role of capsules in gonococcal virulence has not yet been established.

In this study we have examined encapsulated and non-encapsulated variants of one gonococcal strain. The results indicate that they differ in infectivity, serum resistance and antigenic composition.

\section{METHODS}

Gonococci. Strain gc40, originally isolated from the urine of a male with acute urethritis, was used throughout this study. It had been subcultured at least 50 times in vitro when this study was commenced. It did not show capsules by light microscopy using Leishman's stain or did so only occasionally around a few cells and was referred to as variant $\mathrm{N}$. Variant $\mathrm{C}$ was obtained by inoculating variant $\mathrm{N}$ in a rabbit subcutaneous chamber where it produced a mixed infection together with a corynebacterium sp.; after reisolation from the rabbit chamber (a process involving a total of three in vitro cultures) the organism was grown in a guinea-pig chamber as previously described (Demarco de Hormaeche et al., 1978, 1979). It was confirmed as Neisseria gonorrhoeae by oxidase reaction, sugar fermentations (glucose, maltose, lactose) and nitrate reduction tests. After growth in vivo, in either rabbit or guinea-pig chambers, gonococci appeared different from the parent strain showing clear capsules around all cells (Fig. 1). The possible effect of corynebacteria on gonococcal growth in vivo and in vitro is currently under investigation.

In vitro cultures. These were made on $\mathrm{Gc}$ agar (Difco) enriched with $1 \%(\mathrm{w} / \mathrm{v})$ IsoVitaleX (BBL), referred to as GcIv, and incubated at $36^{\circ} \mathrm{C}$ in candle jars. Cultures were not selected for colony type, both variants gave rise predominantly to large colonies, similar to types 3 and 4 of Kellogg et al. (1963). For storage, standard suspensions of gonococci of each variant were made in Greaves' medium (1960), the total volume divided in portions and frozen in liquid nitrogen. A new ampoule was used each time the variants were compared. Variant $\mathrm{C}$ was always used after being subcultured three times in guinea-pig chambers.

Infectivity tests. The open subcutaneous chamber model was used for these tests. Chambers were made by cutting 6 to $8 \mathrm{~mm}$ long sections of vinyl tubing ( $12 \mathrm{~mm}$, autoclavable $\mathrm{PVC}$, Baird and Tatlock). C3H/he mice of either sex, aged from 3-4 months, were implanted with two chambers each and were inoculated 3-4 weeks later, by which time the inflammation had subsided. Chambers were inoculated with $100 \mu 1$ of serial 10 -fold saline dilutions of a freshly prepared suspension of organisms grown for $18-20 \mathrm{~h}$ in plate culture. In most experiments, mice were given both variants of gc 40 simultaneously, one in each chamber. Samples $(100 \mu \mathrm{l})$ were taken at 2 and $5 \mathrm{~d}$ after inoculation and cultured immediately on GcIv medium or chocolate agar. Inoculation and sampling of the chambers were performed with the animals under ether anaesthesia.

Bactericidal test. This was performed in sterile microtitre plates with filter-sterilized complement fixation test (CFT) diluent (Oxoid) containing $0.5 \%$ (v/v) Greaves' medium. Antisera inactivated by heat $\left(56{ }^{\circ} \mathrm{C}\right.$ for $30 \mathrm{~min}$ ) were used and fresh guinea-pig normal serum was used as a source of complement. The guinea-pig serum was titrated to find a dilution which contained complement and had no bactericidal activity.

Serial serum dilutions were made in $50 \mu \mathrm{l}$ volumes and $50 \mu \mathrm{l}$ of a dilution of complement containing two haemolytic doses were added to each well. Gonococci $(50 \mu \mathrm{l})$ were then added from a suspension containing $10^{4}$ c.f.u. $\mathrm{ml}^{-1}$. Controls were made by substituting serum, complement or both with CFT. Reagents and plates were kept on ice during the procedure. Plates, with lids, were finally shaken gently but thoroughly and incubated at $37^{\circ} \mathrm{C}$ for $1 \mathrm{~h}$ and placed in a moist box. After incubation $5 \mu \mathrm{l}$ samples were taken from each well using a multiple channel Finn-pipette and placed on plates of GcIv medium. In this way every dilution was sampled in quadruplicate. Cultures were incubated for $20 \mathrm{~h}$ and the colonies counted. The highest serum dilution killing $50 \%$ of the gonococci was taken as the titre for bactericidal activity.

Antisera. These were obtained by inoculation of gonococci of strain gc 40 into rabbits. Variants $\mathrm{N}$ or $\mathrm{C}$ were subcultured on GcIv medium covered with dialysis tubing to avoid agar contamination. After $18-20 \mathrm{~h}$ incubation, the gonococci were harvested in PBS containing per litre: $8 \mathrm{~g} \mathrm{NaCl}, 0 \cdot 2 \mathrm{~g} \mathrm{KCl}, 1 \cdot 15 \mathrm{~g} \mathrm{Na}_{2} \mathrm{HPO}_{4}, 0 \cdot 2 \mathrm{~g} \mathrm{KH}_{2} \mathrm{PO}_{4}$, pH 7.2 and mixed with equal volume of complete Freund's adjuvant (Difco). Rabbits were inoculated intramuscularly with a total of $1 \mathrm{ml}$ mixture containing $10^{8}$ cells. At days 14 and 20 the rabbits were challenged intravenously with $10^{7}$ gonococci suspended in saline and were bled on day 28 . Sera were kept at $-20^{\circ} \mathrm{C}$.

Saline extracts. Gonococci were subcultured on GcIv medium covered with dialysis tubing and incubated for $18-20 \mathrm{~h}$ at $37^{\circ} \mathrm{C}$, harvested and suspended in saline. Comparable extracts of gc40 $\mathrm{N}$ and $\mathrm{C}$ were made by growing gonococci of each variant under identical conditions and by making suspensions of equal concentration adjusted to give $A_{600}=0.3$ for $1 / 100$ dilutions. The suspensions were centrifuged in a Beckman microfuge at $8000 \mathrm{~g}$ for $5 \mathrm{~min}$, and the supernatants were then termed saline extracts and stored at $-20^{\circ} \mathrm{C}$. 

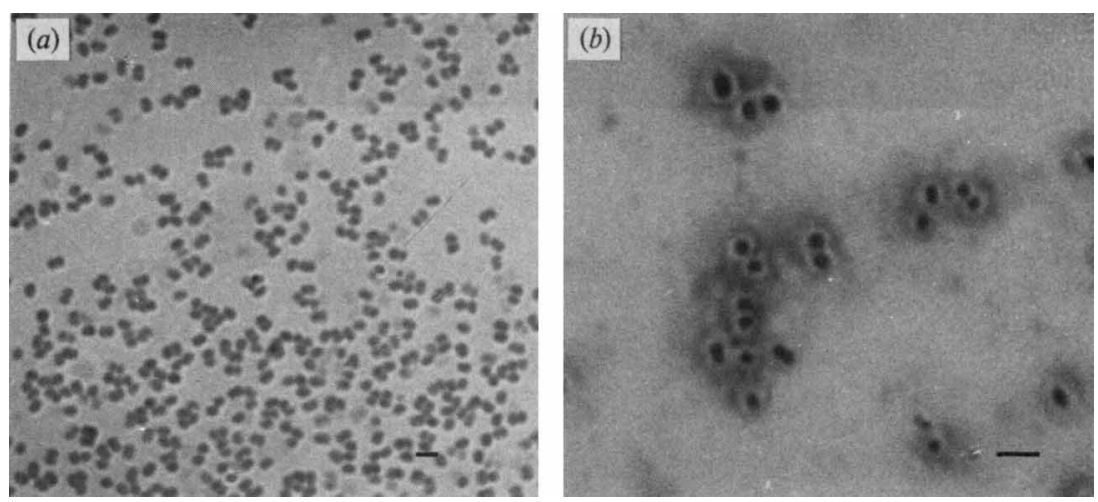

Fig. 1. Light microscopy of gonococci of strain gc40, Leishman stain. (a) Variant $\mathrm{N},(b)$ variant C. The bar markers represent $2 \mu \mathrm{m}$.

LPS extracts. Gonococci were subcultured, harvested and centrifuged as described above. Gonococci were sonicated while kept on ice, using an MSE sonicator. The disrupted gonococci were heated to $69^{\circ} \mathrm{C}$ and an equal volume of hot phenol $\left(95 \%, \mathrm{w} / \mathrm{w}, 69^{\circ} \mathrm{C}\right)$ was added. The extraction was carried out at $69^{\circ} \mathrm{C}$ for 15 min with constant stirring. The preparation was then cooled at $4{ }^{\circ} \mathrm{C}$ and centrifuged at $1000 \mathrm{~g}$ for $10 \mathrm{~min}$. The water phase was collected and kept, while the interface and phenol phase were re-extracted with an equal volume of distilled water.

The aqueous layers of successive extractions were pooled and dialysed against running tap water until no phenol smell was detected. This crude phenol-water extract was freeze-dried, weighed and resuspended in distilled water. Insoluble material was removed by centrifugation at $2000 \mathrm{~g}$ for $10 \mathrm{~min}$. Supernatant was treated with DNAase and RNAase (Sigma) final concentration $10 \mu \mathrm{g} \mathrm{ml}^{-1}$ for $\mathrm{I} \mathrm{h}$ at $37^{\circ} \mathrm{C}$ and centrifuged at $100000 \mathrm{~g}$ for $18 \mathrm{~h}$. After freezedrying of the pellet the enzyme treatment and centrifugation were repeated once. The final pellet was resuspended in distilled water, freeze dried and weighed. Both variants gave similar amounts of LPS; $5 \%$ of the total crude phenol-water extract was recovered as judged by dry weight measurements. The preparations were free of contamination by nucleic acids and proteins as determined by carbocyanine dye assay and measurements of $A_{260}$ and $A_{280}$.

Lipid A was determined by the carbocyanine dye method of Janda \& Work (1971). The 2-keto-3deoxyoctulosonic acid (KDO) was determined colorimetrically by the method of Weissbach \& Hurwitz (1959).

Gel diffusion techniques. These were performed in $1 \%(\mathrm{w} / \mathrm{v})$ agarose (Indubiose A45, I.B.F.) in sodium barbitone buffer $0.043 \mathrm{M} \mathrm{pH} 8.6$ containing $0.01 \mathrm{M}$-sodium azide. Results were recorded with fresh gels or after washing, drying and staining with Coomassie brilliant blue.

Double diffusion. Wells were cut in the gels to contain $18 \mu \mathrm{l}$ volume samples of antigen or antiserum. Saline extracts of gonococci or LPS extracts were treated with aqueous sodium deoxycholate $(0 \cdot 25 \%$ final concentration $\mathrm{pH} 8.4)$ before use. The gels were incubated overnight at room temperature.

Crossed immune electrophoresis $(C I E)$ and crossed affinity electrophoresis. These were performed on $7.5 \times 7.5 \mathrm{~cm}$ glass slides. Separation of the first dimension was carried out in $1 \%(\mathrm{w} / \mathrm{v})$ agarose $(3 \mathrm{ml})$ dispensed on $1 / 3$ of the area of the plate Wells were cut to contain $18 \mu \mathrm{l}$ volume of antigen ( $\mathrm{N}$ and $\mathrm{C}$ preparations were always compared simultaneously at equal volumes). Electrophoresis was carried out for $45 \mathrm{~min}$ at $40 \mathrm{~V}$ measured end to end of the gel. After this $4 \mathrm{ml}$ agarose containing either antiserum $(4 \%, \mathrm{v} / \mathrm{v})$ or one lectin [wheat germ agglutinin (WgA), concanavalin A or Limulus, Sigma] at a concentration of 0.75 to $20 \mu \mathrm{g} \mathrm{ml}^{-1}$ was dispensed onto the rest of the plate and the second dimension was run at $20 \mathrm{~V}$ overnight using a cooling system.

Rocket electrophoresis. Agarose containing WgA $\left(0.75\right.$ to $\left.20 \mu \mathrm{g} \mathrm{ml} \mathrm{m}^{-1}\right)$ was used for this technique and electrophoresis was run overnight at $20 \mathrm{~V}$.

\section{RESULTS}

\section{Infectivity of strain gc40 in mice}

The two variants of strain gc40 showed a marked difference in their infectivity when inoculated into subcutaneous chambers in mice. Non-encapsulated gonococci of variant $\mathrm{N}$ did not infect any of the chambers inoculated at doses varying from $10^{2}$ to $10^{8}$. On the other hand the encapsulated variant was very efficient, producing infection in chambers inoculated with doses 
Table 1. Infectivity of variants of strain gc40 in mouse subcutaneous chambers

The results indicate no. chambers infected/no. chambers inoculated and this is shown as a percentage in parentheses.

$\begin{array}{ccc}\text { Dose (c.f.u.) } & \text { Variant C } & \text { Variant N } \\ 10^{8} & \text { NT } & 0 / 10 \\ 10^{7} & 8 / 10(77 \%) & 0 / 10 \\ 10^{6} & 34 / 45(76 \%) & 0 / 35 \\ 10^{5} & 11 / 22(50 \%) & 0 / 22 \\ 10^{4} & 19 / 37(52 \%) & 0 / 37 \\ 10^{3} & 10 / 18(55 \%) & 0 / 18 \\ 10^{2} & 5 / 10(50 \%) & 0 / 15 \\ 10^{1} & 3 / 10(30 \%) & \text { NT } \\ & \text { NT, Not tested. }\end{array}$

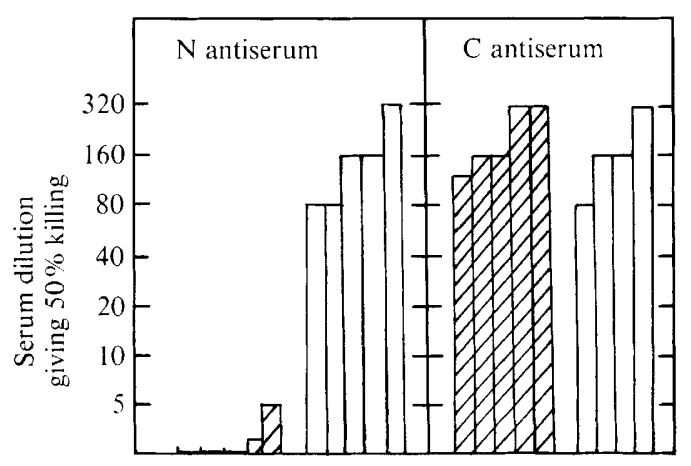

Fig. 2. Effect of encapsulation on resistance to the bactericidal effect of antibody and complement. Each bar represents an individual experiment. $\square$, variant $C ; \square$, variant $N$. These results were consistently seen in repeated experiments (two to five in each case), using antisera raised in different rabbits.

as low as $10^{1}$ gonococci. However, a minimum infectious dose or an infective dose 50 could not be determined for variant $C$ as some of the animals became infected at the lowest dose employed and no differences were seen in the infectivity of doses ranging from $10^{3}$ to $10^{5}$ c.f.u. (Table 1 ).

This clear cut difference in infectivity of the variants was consistently seen in repeated experiments in mice carrying two chambers and inoculated simultaneously with one variant in each chamber.

\section{Resistance to bactericidal effect of specific antibody and complement}

The resistance of the $\mathrm{C}$ and $\mathrm{N}$ variants to the killing effect of antibody and complement was tested in vitro using antisera raised in rabbits by inoculation of either variant. A clear difference was seen in resistance to killing by anti-N antisera. Several anti- $\mathrm{N}$ antisera produced in different rabbits were bactericidal for variant $\mathrm{N}$ but not for variant $\mathrm{C}$ (Fig. 2), suggesting the presence of a different antigen on the surface of variant $\mathrm{C}$. On the other hand, both variants were killed to a similar titre by anti-C antisera.

\section{Reactivity of surface antigens with lectins and antibody in gel diffusion}

Saline extracts of equal quantities of variants $\mathrm{N}$ and $\mathrm{C}$ were tested in CIE against an antiserum to variant $\mathrm{C}$. The two variants were shown to contain different proportions of a number of negatively charged antigens, which gave reactions of identity when tested in tandem. Most of those antigens have been demonstrated to be of cytoplasmic origin (Demarco de Hormaeche, 1979). Extracts of variant $\mathrm{N}$ showed one precipitation line near the antigen well indicating the presence of a slow moving antigen in the preparation. Extracts of variant $\mathrm{C}$ 

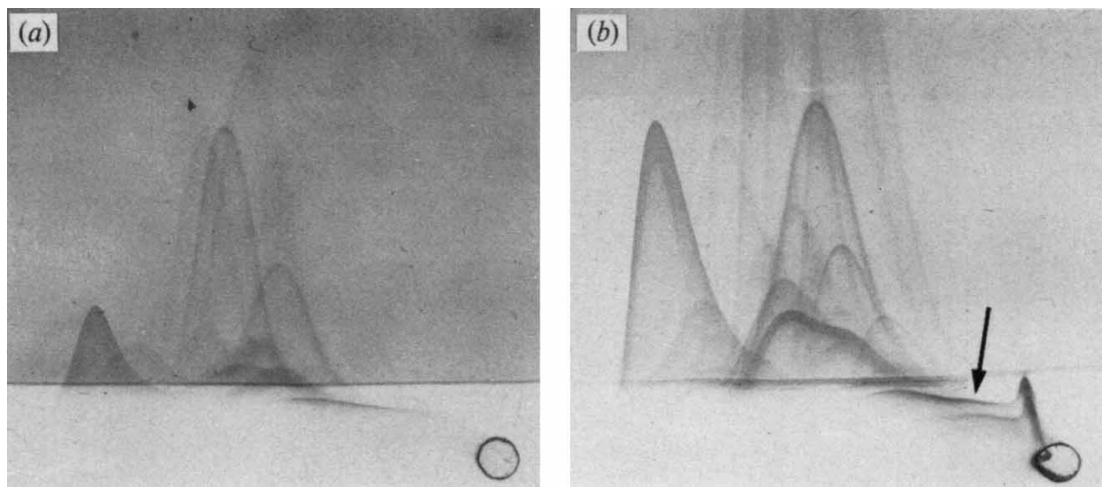

Fig. 3. CIE of saline extracts of gonococci of strain gc40 against antiserum to variant C. (a) Variant N, (b) variant $C$. Though present in different relative amounts, all but one antigen (arrow) were shown to be present in both variants when preparations were tested in tandem.

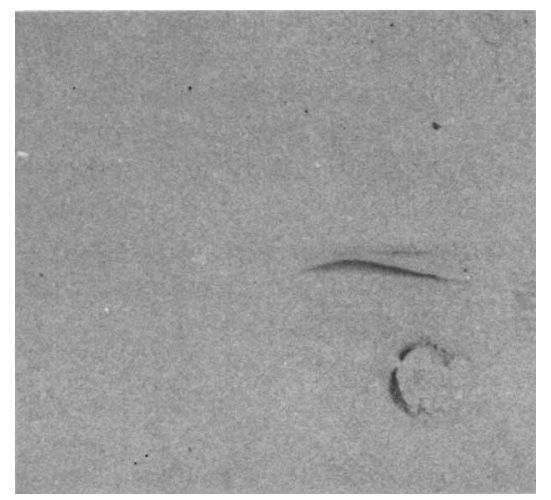

Fig. 4. Crossed affinity electrophoresis of variant $\mathrm{C}$ saline extract with $5 \mu \mathrm{g} \mathrm{WgA} \mathrm{m}{ }^{-1}$ in the second gel. Only one precipitation line is formed.

showed two precipitation lines near the origin well suggesting the presence of an extra antigen in this variant (Fig. $3 a, b$ ), which did not give reactions of identity when the preparations were run in tandem.

Crossed affinity electrophoresis of the saline extracts using $\mathrm{WgA}$ in the second dimension showed a difference in the reactivity of variants $\mathrm{N}$ and $\mathrm{C}$. Extracts of variant $\mathrm{N}$ did not form precipitation lines with $\mathrm{WgA}$ at any of the concentrations tested while extracts of variant $\mathrm{C}$ gave a distinct line of precipitation at an optimum concentration of $5 \mu \mathrm{g} \mathrm{WgA} \mathrm{ml}^{-1}$ (Fig. 4). This single precipitation line appeared at the location in which an extra antigen was seen in extracts of variant $\mathrm{C}$ by CIE (arrow in Fig. $3 b$ ). No reactions were detected using concanavalin $\mathrm{A}$ or Limulus in the second gel.

\section{Reactivity of LPS extracts with antibodies and $\mathrm{WgA}$}

Matching LPS preparations extracted from variant C (C LPS) and variant N (N LPS) were shown to contain equal amounts of lipid $A$ and also very similar proportions of $\mathrm{KDO}: 6.2 \%$ for $\mathrm{N} \mathrm{LPS} \mathrm{and} 6.4 \%$ for C LPS. However they differed greatly in their reactivity with $\mathrm{WgA}$ and specific anti gc40 antisera. Whereas, N LPS did not form precipitation rockets with WgA at any of the concentrations of lectin tested $\left(0.75-20 \mu \mathrm{g} \mathrm{ml}^{-1}\right)$, C LPS gave rockets at various concentrations with an optimum at that of $2.5 \mu \mathrm{g} \mathrm{WgA} \mathrm{ml}{ }^{-1}$ (Fig. 5). Differences between $\mathrm{N}$ and C LPS were also found using the double diffusion technique. C LPS reacted with anti 


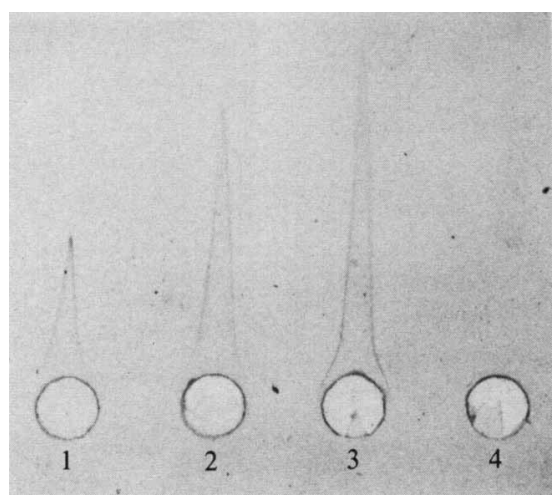

Fig. 5. Rocket electrophoresis of LPS preparations into agarose containing $2.5 \mu \mathrm{g} \mathrm{WgA} \mathrm{ml}^{-1}$. LPS from variant $\mathrm{C}$ formed neat rockets at all concentrations tested $\left(0 \cdot 5\right.$ to $2 \mathrm{mg} \mathrm{LPS} \mathrm{m}^{-1}: 1$ to 3$)$ while LPS from variant $\mathrm{N}$ (shown here at the concentration of $2 \mathrm{mg} \mathrm{ml}^{-1}, 4$ ) did not.

variant $\mathrm{C}$ antiserum forming a single precipitation line. N LPS also produced a precipitation line with this antiserum but gave a reaction of only partial identity with C LPS antigen demonstrating the presence of a different antigenic determinant in the latter (Fig. 6a). The antigens detected in the LPS preparations by the anti variant $C$ antiserum were also found in the saline extracts of the corresponding variants. Absorption of the variant $C$ antiserum with N LPS removed all its reactivity with N LPS but the antibodies reacting with C LPS and antigens of the surface washes remained in the antiserum (Fig. 6b). Absorption with C LPS removed antibodies directed to either LPS, the antiserum reacted only with antigens present in the saline extracts and apparently unrelated to the LPS (Fig. $6 c$ ).

\section{DISCUSSION}

An encapsulated variant of gonococci of strain gc 40 selected by in vivo growth was infective when inoculated into subcutaneous chambers implanted in mice, while the parent strain was not; the encapsulated variant was no longer killed by antibodies directed to the parent strain. An additional antigen determinant was detected in saline extracts and LPS extracted from washed bacteria of the variant $\mathrm{C}$ compared with variant $\mathrm{N}$.

Although saline extracts were expected to contain the capsular material, attempts to demonstrate a capsular polysaccharide distinct from the LPS, have not so far succeeded (unpublished observations). It is not known whether some properties of the C LPS may give rise to the morphological appearance of a capsule and this is under investigation at the moment. It is still possible that the observations of differences in encapsulation and differences in antigenic structure of the LPS between the variants $\mathrm{N}$ and $\mathrm{C}$ may relate to two independent properties.

The resistance to killing by fresh human sera of gonococci in human pus demonstrated by Ward et al. (1970) was lost after one subculture, and similar observations have been made by Penn et al. $(1976,1977)$ and Rittenberg et al. (1977) on gonococci in subcutaneous chamber fluid. However, the serum resistance reported here for gonococci of variant $\mathrm{C}$ was maintained for at least three cultures in vitro, indicating that serum resistance was not determined by phenotypic change, the protective effect of substances present in inflammatory exudate or by the intracellular location of the gonococci.

The morphological appearance of capsules has been revealed by electron microscopy of preparations fixed in the presence of Alcian blue of gonococci of strain gc 40 recently grown in vivo (Demarco de Hormaeche et al., 1978) or gonococci grown on a special medium (Hendley et al., 1981). Encapsulation could explain the serum resistance seen in variant $\mathrm{C}$ as the capsule would provide a surface layer for which anti variant $\mathrm{N}$ antisera would not possess antibody. The capsule might then protect the outer membrane from the lytic effect of antibody and 

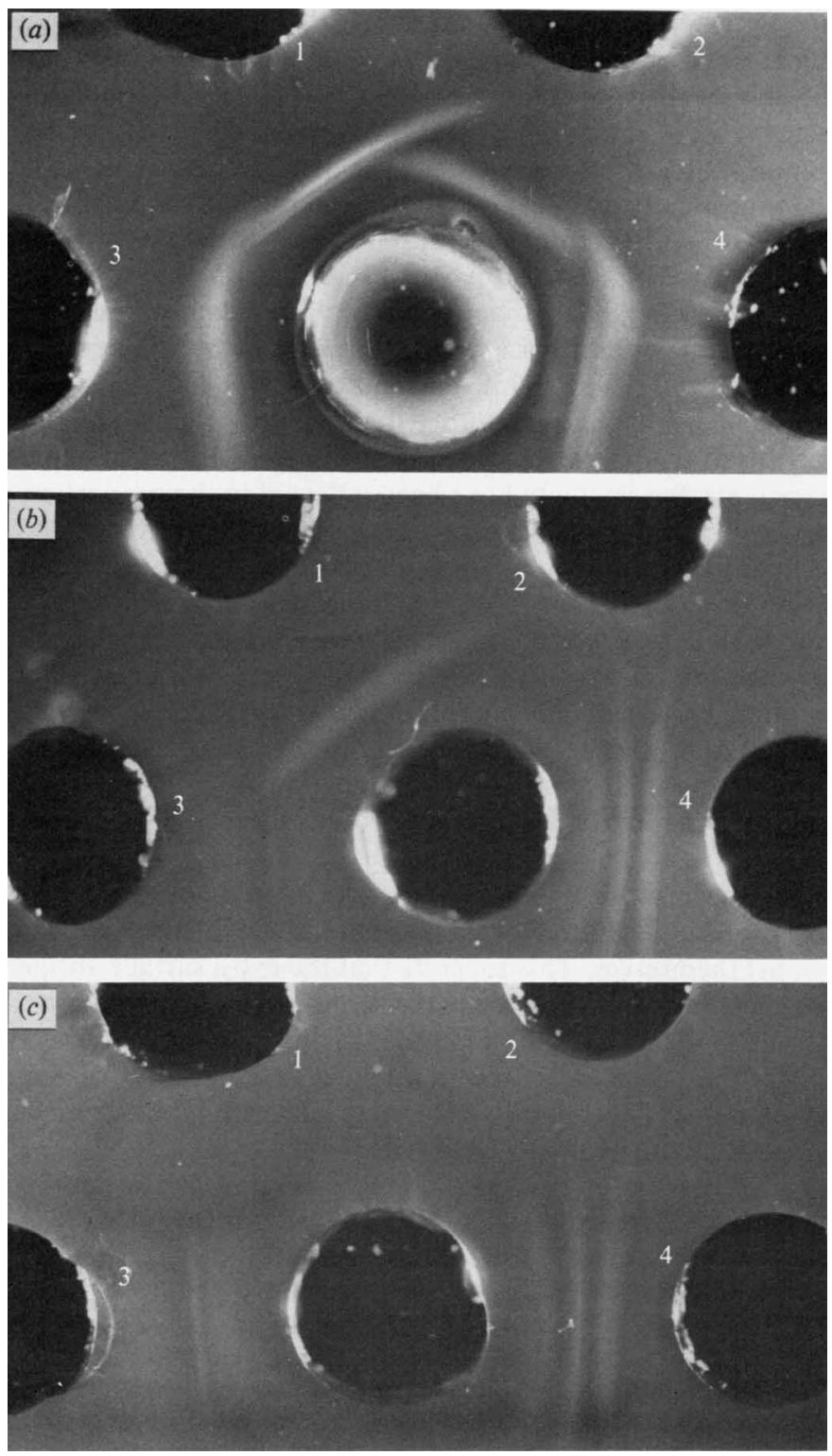

Fig. 6. Immunodiffusion of antigen extracts from $\mathrm{N}$ and $\mathrm{C}$ variants. C LPS (1), N LPS (2), and saline extracts of variant $C(3)$ and variant $N(4)$ were tested against $(a)$ an anti variant $C$ antiserum, $(b)$ the same antiserum after absorption with N LPS or $(c)$ the same antiserum after absorption with C LPS.

complement. A similar effect has been demonstrated by Glynn \& Howard (1970) in E. coli; K antigens confer resistance to the bactericidal effect of antibody and complement which act on the outer membrane antigen and the protection conferred is proportional to the amount of $\mathbf{K}$ antigens formed.

In this study an antigen absent in the parent strain was demonstrated in the encapsulated in vivo grown variant using gel precipitation techniques. This antigen was found in the saline extracts and also in isolated LPS and it is likely that it is involved in the reaction with WgA. It seems also likely that it corresponds with the antigen of in vivo grown gonococci shown to react with WgA by Perera et al. (1980). Allen et al. (1980) demonstrated the presence of sugars on the 
gonococcal surface with terminals corresponding with the specificity of WgA ( $N$-acetyl-Dglucosamine) using an agglutination technique. They showed these sugars in the LPS and in the LPS derived acidic polysaccharides described by Apicella $(1974,1976)$ and suggested that lectin binding is mediated by LPS, involving elements of common core structure.

In this investigation, extracts from our isogenic virulent and avirulent gonococci were shown to have different antigenic specificity and $\mathrm{WgA}$ reactivity. LPS extracted from variant $\mathrm{C}$ gonococci bound $\mathrm{WgA}$ while $\mathrm{LPS}$ from variant $\mathrm{N}$ did not, demonstrating chemical differences in the sugar terminals of LPS molecules. At the same time, double diffusion technique using anti-virulent gonococci antisera clearly showed an antigenic determinant in C LPS which was absent in the $\mathbf{N}$ variant. Changes in the LPS structure are known to influence virulence variation in enterobacteria (Wilson and Miles, 1975). Variants of salmonella possessing S-type LPS (with side chains) are virulent while variants with R-type LPS (without side chains) are not. The presence of side chains in the polysaccharide portion of our LPS could explain the differences seen between the variants, but it should have been reflected in the proportion of KDO in the $\mathrm{C}$ and N LPS preparations. Since both LPS preparations had similar lipid A and KDO contents it seems likely that alterations in $\mathrm{WgA}$ binding and antigen specificity were caused by alterations in sugar composition or configuration of the oligosaccharide portion of the LPS rather than acquisition of additional polysaccharide side chains. Structural differences in the LPS molecule of isogenic pyocin resistant and sensitive gonococci have been reported (Connelly et al., 1981) and changes in the configuration of gonococcal LPS have also been suggested as determinants of variation in human serum resistance (Schneider et al., 1982). It seems possible that variations on the LPS might be important in gonococcal virulence in as much as a change in the LPS molecular configuration might render the gonococcus resistant to bactericidal or opsonic antibodies.

Finally, although gonococci with C LPS and encapsulated appearance are resistant to the bactericidal effect of antibodies directed to the parent strain, they are killed effectively by antisera raised against themselves. This suggests that the extra surface antigen seen in virulent variant $\mathrm{C}$ gonococci acts as a target antigen in the serum bactericidal reaction as long as specific antibodies are present. It seems likely that in order to obtain effective protection to gonococcal infection what should be promoted is the production of antibodies directed to a particular antigen involved in immune lysis. It is possible that the determinant that we describe here in the LPS of virulent gonococci might be one such site.

We are grateful to Professor P. Wildy for his interest and advice. R.D.H. and M.J.T. were supported by Medical Research Council grants.

\section{REFERENCES}

Allen, P. Z., Connelly, M. C. \& Apicella, M. A. (1980). Interaction of lectins with Neisseria gonorrhoeae. Canadian Journal of Microbiology 26, 468474.

APICELla, M. A. (1974). Antigenically distinct populations of Neisseria gonorrhoeae: isolation and characterization of the responsible determinants. Journal of Infectious Diseases 130, 619-625.

APICELla, M. A. (1976). Serogrouping of Neisseria gonorrhoeae: identification of four immunologically distinct acidic polysaccharides. Journal of Infectious Diseases 134, 377-383.

Arko, R. J., Bullard, J. C. \& Duncan, W. P. (1976). Effects of laboratory maintenance on the nature of surface reactive antigens of Neisseria gonorrhoeae. British Journal of Venereal Diseases 52, 316-325.

Brown, W. J., LuCAS, C. T. \& KuHN, U. S. G. (1972). Gonorrhoea in the chimpanzee. Infection with laboratory passed gonococci and by natural transmission. British Journal of Venereal Diseases 48, 177178.
Connelly, M. C., Stein, D. C., Young, F. E., Morse, S. A. \& AlLEN, P. Z. (1981). Interactions with lectins and differential wheat germ agglutinin binding of pyocin 103 sensitive and resistant Neisseria gonorrhoeae. Journal of Bacteriology 148, 796-803.

DEMARCO DE HORMAECHE, R. (1979). Surface antigens of the gonococcus grown in vivo and their role in pathogenicity. Ph.D. thesis, University of Cambridge.

Demarco de Hormaeche, R., Thornley, M. J. \& Glauert, A. M. (1978). Demonstration by light and electron microscopy of capsules on gonococci recently grown in vivo. Journal of General Microbiology 106, 81-91.

GlynN, A. A. \& Howard, C. J. (1970). The sensitivity to complement of strains of Escherichia coli related to their $\mathrm{K}$ antigens. Immunology 18, 331-346.

GrEaves, R. I. N. (1960). Preservation of living cells by freeze-drying. Annals of the New York Academy of Sciences 85, 723-728.

GuYmon, L. F., Lee, T. J., Walstad, D., Schmoyer, 
A. \& Sparling, P. F. (1978). Altered outer membrane components in serum-sensitive and serumresistant strains of Neisseria gonorrhoeae. In Immunobiology of Neisseria gonorrhoeae, pp. 139-141. Edited by G. F. Brooks, E. C. Gotschlich, K. K. Holmes, W. D. Sawyer \& F. E. Young. Washington: American Society for Microbiology.

Hendley, J. O., Powell, K. R., Salomonsky, N. L. \& RoDEwaLD, R. R. (1981). Electron microscopy of the gonococcal capsule. Journal of Infectious Diseases 143, 796-801.

JANDA, J. \& WORK, E. (1971). A colorimetric estimation of lipopolysaccharides. Federation of European Biochemical Societies Letters 16, 343-345.

Kellogg, D. S., Peacock, W. L., Deacon, W. E., Brown, L. \& PiRkLe, C. I. (1963). Neisseria gonorrhoeae. I. Virulence genetically linked to clonal variation. Journal of Bacteriology 85, 1274-1279.

LAMBden, P. R., Heckels, J. E., JAMES, L. T. \& WATT, P. J. (1979). Variations in surface protein composition associated with virulence properties in opacity types of Neisseria gonorrhoeae. Journal of General Microbiology 114, 305-312.

Lucas, C. T., Chandler, F., Martin, J. E. \& Schmale, J. D. (1971). Transfer of gonococcal urethritis from man to chimpanzee. An animal model for gonorrhoea. Journal of the American Medical Association 216, 1612-1614.

Mahoney, J. F., Van Slyke, C. F., Cutler, J. C. \& BLUM, H. L. (1946). Experimental gonococcal urethritis in human volunteers. American Journal of Syphilis, Gonorrhoea and Venereal Diseases 30, 1-39.

Penn, C. W., Sen, D., Veale, D. R., Parsons, N. J. \& SMITH, H. (1976). Morphological, biological and antigenic properties of Neisseria gonorrhoeae adapted to growth in guinea pig subcutaneous chambers. Journal of General Microbiology 97, 35-43.

Penn, C. W., Veale, D. R. \& Smith, H. (1977). Selection from gonococci grown in vitro of a colony type with some virulence properties of organisms adapted in vivo. Journal of General Microbiology 100 , $147-158$
Perera, V. Y., Penn, C. W. \& Smith, H. (1980). The use of specific antiserum induced by lectin-antigen complexes to investigate the outer membrane antigens of Neisseria gonorrhoeae. Journal of Immunological Methods 37, 175-180.

Perry, M. B., Daoust, V., Johnson, K. G., Diena, B. D. \& Ashton, F. E. (1978). Gonococcal R-type lipopolysaccharide. In Immunobiology of Neisseria gonorrhoeae, pp. 101-107. Edited by G. F. Brooks, E. C. Gotschlich, K. K. Holmes, W. D. Sawyer \& F. E. Young. Washington: American Society for Microbiology.

RichaRdson, W. P. \& SAdofF, J. C. (1977). Production of a capsule by Neisseria gonorrhoeae. Infection and Immunity 15, 663-664.

Rittenberg, S. C., Penn, C. W., Parsons, N. J., Veale, D. R. \& Smith, H. (1977). Phenotypic changes in the resistance of Neisseria gonorrhoeae to killing by normal human serum. Journal of General Microbiology 103, 69-75.

SCHNEIDER, H., MCLEOD GRIFFISS, J., Williams, G. D. \& PIER, G. (1982). Immunological basis of serum resistance of Neisseria gonorrhoeae. Journal of General Microbiology 128, 13-22.

WARD, M. E., WATt, P. J. \& GlynN, A. A. (1970). Gonococci in urethral exudates possess a virulence factor lost in subculture. Nature, London 227, 382384.

Ward, M. E., Lambden, P. R., Heckels, J. E. \& WATT, P. J. (1978). The surface properties of Neisseria gonorrhoeae: determinants of susceptibility to antibody complement killing. Journal of General Microbiology 108, 205-212.

WeisBaCH, A. \& HuRwitz, J. (1959). The formation of 2-keto-3-deoxyoctonate in extracts of Escherichia coli. I. Identification. Journal of Biological Chemistry 234, 705-709.

Wilson, G. S. \& Miles, A. A. (1975). Topley and Wilson's Principles of Bacteriology, Virology and Immunity, 6th edn, chapters 8 and 9. London: Edward Arnold. 